\title{
An Investigation of Authenticity in a Nepalese Secondary ESL Textbook and its Supplementation
}

Lekh Nath Baral

\begin{abstract}
This article starts with a brief discussion of the concept of authenticity of language learning/teaching materials followed by an introductory discussion of Nepal's school level English curriculum. Moving away from the conventional notion of authenticity which only takes 'textual authenticity' on board, the present article investigates the authenticity of a text material from the perspective of learner and task along with the textual authenticity and presents supplementation of the material under investigation.
\end{abstract}

Key words: authenticity, curriculum, learner-centeredness, supplement(ation), task

\section{Introduction}

With the origin and spread of the communicative approach to teaching language for a few decades now, the idea that the language teaching/learning materials should be 'authentic' is widely emphasized (e.g. Nunan, 1988:99;Harmer 2001:205; Mishan, 2005). In talking about authenticity, the initial focus was on the authenticity of text or the language input learners obtain which as Breen (1985) observes is only one kind of the authenticity. Arguing that a language lesson is an event, he suggests the consideration of learner, learning and the classroom along with the input (text) when thinking about the authenticity. As the communicative approach is now largely engrained in language teaching in the western world, and is being further enhanced by the revolution in Information and Communication Technology (Mishan, 2005), it has also created a wave of interest in that part of the world where teaching and learning is still under-resourced and has not been able to use the resources of internet, email and equipments like multimedia, and interactive whiteboards.
After the political change in Nepal in 1990 (Houfton et al. 1999), the democratic government initiated change and reform in the education sector following the recommendation of High Level National Education Commission 1990 (Curriculum Development Centre (CDC), 2007a). The curriculum introduced in 1999 was repackaged in 2007 as felt necessary after the political transformation in 2007 which eventually resulted in the downfall of monarchy in May 2008 (Mountain news 2008). As this political transformation had no direct influence in the English curriculum, the new curriculum was inclined towards adaptation of the communicative/ functional approach of the second language teaching (CDC, 2007a). As a result, curricula and textbooks were designed so as to introduce 'authenticity' in the textbook materials. Hence this paper, I will examine the authenticity in a current school level ESL textbook in Nepal from three perspectives viz. text, learner and task. The fourth element of the authenticity, namely situation (Nepal's Secondary education context) will be discussed in the beginning as a framework or basis for discussing 
other three kinds of authenticity. I will also suggest some supplementary tasks as ways of integrating the authenticity into the materials included in the textbook. In the concluding discussion, the implications of the process of supplementation and its limitations will be considered.

\section{School Level English \\ Education in Nepal}

The present school level curriculum was introduced in Nepal in 1999 and it was slightly reorganized in the year 2007seeing language "as a skill that allows one to get things done" through language functions (CDC, 2007a, p. 19). However, on the other hand, the assessment system has not been able to incorporate the functional elements. A close look at the collection of SLC examination papers (Tamang, 2008) indicates that a large part of the examination is still conducted in the traditional format where students answer the questions referred to the textbook materials or based on memory although the provision for an oral test (which carries 25\% marks) has been made which requires students' to appear in a separate listening examination with objective comprehension questions and a speaking test involving interview questions (CDC, 2007a, p. 30). As a result, most teachers are more concerned about how they can help their students get through the traditional examination rather than incorporating the 'new' communicative elements (e.g. giving directions, expressing problems, likes, dislikes etc.) into their teaching. This is particularly true because the success of the teaching and learning program is largely evaluated on the basis of students' success in the examination, where there is not incorporation of the communicative element. Schools are likely to obtain more government subsidy if they have good examination results over a period of year, and the teachers with best results in their subjects are more likely to get reward from the management. On the other hand, while the ESL curriculum aims to develop students' understanding and participation in various authentic language skills i.e. listening, speaking, reading and writing (CDC, 2007a pp. 19-21), the prescribed textbook lacks the elements of authenticity, which is at the centre of the communicative/functional approach to teaching.

Authenticity has thus, the role to help learners to experience 'real' or real like use of language so that they can learn to use language to carry out communicative functions.

According to Littlewood (1981), communicative language teaching pays attention to functional as well as structural aspects of language. Nunan (1988) also highlights the principle of communicative teaching which sees the importance of using language to "get things done" (p. 25) for enabling learners to carry out real-world tasks without neglecting the role of structure (grammar). From the perspective of a teacher/learner, communicative authenticity thus involves not only the input, but also the aspects of participants (teacher, students) and purpose of the communicative event or task.

\section{What is Authenticity?}

The notion of authenticity is widely discussed in ESL literature (e.g. Breen, 1985; Mishan, 2005; Widdowson, 1978, 2003) but is not beyond controversies and confusions (Taylor, 1994). Some authors (e.g. Van Lier, 1996; Widdowson, 1979) see authenticity as achieved by the participants in the process of exploitation of text or materials whereas there are essentialist views (e.g. Harmer 2001; Nunan, 1989) that see authenticity as a feature inherent in the texts (materials) which can be used in a language classroom. There is yet another orientation to this notion which sees authenticity as situated in the classroom, culture or the purpose of the use (Bachman, 1991; Kramsch, 1993; Guariento \& Morley, 2000). Authenticity for a classroom teacher is integrative of these different notions where a text input, the way participants exploit it and what they want to achieve with this exploitation require equal consideration.

One of the advantages of using authentic materials, as the essentialists suggest, is that they are supposed to provide 'native speaker' use of language which have real purpose and offer model of language use for its learners. However, that assumption is problematic in the context of language use and 
its learning. Firstly, the idea of 'native speaker' authenticity is blurred because English is used by more non-native speakers than native speakers (Crystal, 1997) in diverse contexts and disciplines for real communicative purposes; and it is also argued that it is not native English but lingua-franca English that most ESL learners need to acquire (Ur,2008). Secondly, if the goal of using authentic materials is to offer 'models' of target language use to the learners, we cannot conclude that every native speaker's use of language provides a 'model'. For example: expressions like innit cannot be regarded as appropriate use of language, even if they are native samples (ibid.).Thirdly, the idea that language used for a 'real purpose' (e.g. shopping, booking a ticket) is authentic is also problematic, because whatever the context is, if any communication takes place between people who understand each other, a communicative purpose is achieved. Therefore, it can be argued that the best option is to offer the competent use of language, whether native or nonnative, as a model. In the context of this paper, I take the point from Breen (1985) that "what is authentic is relative to our purposes in the classroom and to the points of view of the different participants in that classroom" (pp. 60-61).

\section{The Grade 10 English Textbook of Nepal}

For authenticity analysis and supplementation, I have used the textbook that is prescribed for secondary level grade 10 students (15-17 years) of Nepal (CDC, 2007b). Although the private schools (almost all of them use English as a medium of instruction) in Nepal use textbooks published by different publishing houses, they use the textbooks published by CDC especially for School Level Certificate (SLC) level students. Government schools on the other hand use the text-books of CDC at all levels. As a result all the students studying at grade 10 across the country use the same textbook. This uniformity is due to the fact that all students (studying at private or government schools) sit for the same SLC examination where students are required to answer some textbook based questions as well. Therefore, I chose the material thinking that this was the material which is used by every
SLC student all over Nepal regardless of the type of schools he/she studies in. Along with this textbook, teachers and students in some schools use exam preparation guides or practice books (e.g. Tamang, 2008) available in the market.

The textbook materials (CDC, 2007b) follow the frame and pattern as prescribed by the curriculum (CDC, 2007a). There are 19 units in total, which are structured around different language functions/ genres. Each unit includes a reading text as input for other language skills: speaking, writing, listening as well as grammar. The typical unit begins with some pre-reading questions followed by a reading text (Poem, Drama, Memoir, Letter etc.) and some post-reading comprehension activities (vocabulary, comprehension questions, completion etc.). Based on the reading input, students engage in some writing tasks (paragraph, dialogue etc.). There are exercises in each unit where students are required to work in pairs or groups to participate in verbal communication prompted by clues or guidelines. Towards the end of each unit they have a short listening comprehension task which often involves listening to audio material(s) produced for pedagogic purposes. Some grammar exercises are given, but explicit grammar teaching is discouraged. The teaching learning process, as the curriculum states, is learner-centered, where the teacher provides students with opportunity to use language (ibid.). The curriculum also prescribes methods and strategies like demonstration, question and answer, guessing, role play, group and pair work and discovery technique. Although there is prescription of continuous assessment of students' progress, the final SLC examination is external and there is no account taken of this assessment. From the assessment perspective, reading and writing skills are more important than listening and speaking, as they carry $75 \%$ of the full marks.

\section{Text Authenticity}

An authentic text is the text which is not primarily meant to be used in the language classroom but for the fulfillment of the social purpose in the target language community (Little et al. 1989). As was 
discussed already, there is not much controversy among scholars in what actually text authenticity means. The main point about text authenticity relates to the 'reality' or 'naturalness' or 'genuineness' of the stretch of language. The essentialist view that authenticity is inherent in the language that is being used in 'native' social context mostly concerns with text authenticity. However, Widdowson (1987) distinguishes the notion of genuineness from authenticity. For him it is the relationship between the text and its receivers that decide the authenticity as every stretch of language in use is not encountered by or cannot interest every native language user. While on the one hand the genuine materials lose their context when presented as extracts, they might not relate to the "existing context knowledge" of the receiver failing to interest them (ibid. 80) on the other. The notion of the authenticity thus goes beyond what is inherent to where it is used and how it is responded to.

The communicative thrust behind using an authentic text in the classroom has been that students acquire "effective receptive competence" by getting input of the language of the real world (Guariento \& Morley, 2001 p. 347). However, there lies the challenge of the selection and presentation of real stretch of language that is effective to the audience who are supposed to attend to it. According to Widdowson (1978) such authenticity can be achieved by 'pedagogic contrivance', that is to link the text with the subject areas that students might be interested in or by associating it with their L1. While the process of 'contrivance' is crucial, it is not limited only to linking with other subject areas and associating to learners' L1 in foreign language context. There are many options for the materials developers and teachers in this regard (magazines appropriate to the level and interest of learners, newspaper reports and advertisements, television and radio programs, the internet etc.) because English language is widely used all over the world for 'genuine' purposes by many non-native users of it. While those options are being gradually available in the ESL/EFL situations in many parts of the world, consideration of the learners' background knowledge, hobbies and interests, cognitive ability and their awareness of the purpose for which they are learning the Target Language (TL) needs to be made in selecting those materials. In Nepal's situations where learners learn English as a subject on which they require to pass their examination, they might not be aware of the intended purpose for which they are learning English because they do not learn English by choice but by compulsion. In this context, it is the teacher's responsibility to exploit the materials as per the curriculum goals. Similarly, if the authentic language is believed to communicate information, it can be outdated by the time it appears in materials (especially using printed and recorded materials) (Little et al. 1989) which means it is the teachers' responsibility to update or supplement such text so as to give relevant information.

The role of the classroom teacher is thus very crucial in the selection of simple authentic texts considering the cognitive and linguistic levels of the learners. In this regards it is more important to note that what we do with the materials is more important than its genuine use (Mishan, 2005).

\section{Learner Authenticity}

While the traditional notion of authenticity relates to the text that is meant for real communication and not for the classroom purpose, we have to consider many factors while selecting such texts. In a natural language setting, there can be thousands and even millions of such samples both in written and spoken form and it is not always easy to decide which of those samples to be brought to the classroom. Moreover, there is a choice in real language setting on the part of the receivers to attend or not to attend to the language produced. Breen (1985) and Widdowson (1987) question the authenticity of real texts arguing that it is dependent upon who receives them. While used in the classroom setting, it is obvious that the recipients of information brought by the text are the learners. As the materials that resemble the reality of the target context are aimed at proficient user of that language, the learners of that language might fail to appropriately interpret the meaning of that material. Therefore, the authentic materials need to be motivating, 
interesting, useful and culturally appropriate to the learners (Young, 1980 cited in Lee, 1995 p. 324). To ensure that the materials are learner authentic, the materials developers and teachers should make them linguistically comprehensible (just beyond the level of linguistic competence) (Krashen, 1982), and cognitively demanding that requires students to think and guess. The content of the material should be appealing and the information available should be useful to the learners.

Is it possible for a textually authentic material to ensure all the aspects of 'learner authenticity' as discussed above? Lee (1995) opines that the textually authentic materials have that potential as they have "intrinsically communicative quality" (p. 324). However, Widdowson (1998) proposes localization of text into the learners' context arguing that "the classroom cannot provide the contextual conditions" (p. 711) for learners to authenticate the real texts because they are outsiders for context and the meaning the text brings. As discussed earlier, it is possible these days to use localized texts as we can find different kinds of English language materials being produced in different parts of the world even in non-native settings. Similarly, using classroom use of students/teachers can also serve the purpose of a learner as well as text authenticity where localized materials are not sufficiently available. Thus, the idea of learner authenticity can be useful for the teachers to think about while selecting a textmaterial in their context.

\section{Task Authenticity}

Identifying six criterial features, Ellis (2003, pp. 9-10) describes task as i) "a workplan" of the teacher which might require renegotiation in the course of teaching, thus, might not result in communicative outcome, involving ii) "primary focus on meaning", iii) "real-world processes of language use", iv) "any of the four language skills”, v) engaging students in "cognitive processes" vi) for "a clearly defined communicative outcome". Similarly, Samuda \& Bygate (2008, pp. 13-16) identify eight characteristic features of a task: holistic language use, meaningful outcome(s), input material, process of progression, steps or sub-task activities, opportunity to 'notice' language or structure being targeted, possibilities of manipulation as per the situation and possibilities of its use to obtain different purposes. From pedagogic authenticity perspective, Samuda \& Bygate's (ibid.) features are more comprehensive in that they cover aspects of language input and take the importance of language form on board without undermining the reality of language use. They highlight the use of language holistically, involving both the productive and receptive skills in task progression. Moreover, while Ellis opines that tasks may not necessarily result in communication, Samuda \& Bygate focus on communicative outcome as being essential.

An authentic task demands students to engage in an activity which has authentic purpose requiring actual or real language use in the classroom. Breen (1985) makes a distinction between authentic communication task and authentic language learning task and recommends that we should choose such tasks which "involve the learners not only in authentic communication with texts and with others in the classroom, but also about learning and for the purpose of the learning" (p. 66). Nunan's (2004) view of a task is closer to the language learning authenticity than the communicative authenticity as he prefers to use the term task in pedagogic sense to refer to the meaning focused communicative use of language in classroom, distinguishing it from target (real-world) tasks which refer to the communication activities beyond the classroom. Ellis (2003) has a slightly different opinion on authenticity of tasks. Although he also distinguishes tasks as involving situational (real-world) or interactional (potentially real-world) authenticity, he opines that classroom tasks can have elements of both situational and interactional authenticity. Arguing that the strong form of tasks (tasks as representing the communication in real-world situation) cannot be authenticated, Widdowson (2003) talks about contrived language use where we can "approximate more closely to the reality of use" (p. 112) because classroom contexts differ from the contexts within which the language is used. Nunan (2004) also sees the importance of transforming real-world tasks into pedagogic tasks for creating learning 
opportunities which "can be placed on a continuum from rehearsal tasks to activation tasks" (p.19). By rehearsal tasks, he means the activities that students engage in class as resembling to the activities they are required to carry out of the classroom whereas activation tasks require students to engage in language functions which may not necessarily resemble to the real-world communication. In the similar vein, Mishan(2005, p.74) asserts that the matter of genuine authenticity is not only related to the resemblance of the real language use but also with the aim of the communicator which can be a practical outcome or specific to the language classroom. In the context of the curriculum and textbook under discussion, my view of the task is similar to pedagogic task as used by Nunan (2004) where students have to engage in some interactional work taking the given context as a springboard.

In fact it is the task authenticity that incorporates both textual as well as learner authenticity because it demands communication between and among the learners based on the input available to them.

So far I have presented my discussion of different kinds of authenticity and how these different views are taken on board while investigating authenticity. In the following section, I present an investigation of authenticity in a unit in the textbook that is in use in the secondary schools in Nepal. I have examined the elements of text, learner and task authenticity on the basis of the above discussion.

\section{Authenticity in the Nepalese Secondary School Text-book and its Supplementation}

The reading text in the original material (CDC, 2007b, see Apendix 1) is author created and the information the text brings is artificial. Although the information that the text brings is authentic in the TL culture, the authors have adapted the names and locations to the students' local context, as a result, the text becomes inauthentic both in the TL and L1 contexts. Moreover, the text fails to offer sufficient input for the following activities. For example, the students are required to match the pictures with the words in page 32 but there is not any contextual information given in the text. Therefore, an additional text (Appendix 2) is presented which is in fact a letter written by one of students to her class teacher. In using the letter, I have adapted the name and the address used in the original letter so as to respect the privacy of the author. The information that the text brings is authentic in the social context of the learners. As the content of the original text does not offer sufficient ground for the activities that follow, the supplementary text tries to offer context (input) for all the tasks. The supplementary text (Appendix 2) satisfies textual authenticity on the following grounds:

1. The text is an adaptation of an original letter written by a high school student to her teacher.

2. The context and content of the text is very much related to the society/community that surrounds the daily lives of the students.

3. The original text is within the cognitive level of the students and not beyond their level of comprehension as it is authored by a student like them. However, attempts have been made to introduce some new vocabulary and structure without distorting the message of the text so as to make it suitably challenging to the students.

4. The text is likely to be motivating to the learners because the content can arouse sympathy/ empathy of the readers to the author of the text.

The present curriculum and textbook accordingly stress the learner-centred activities in the classroom where the teacher is a guide and a facilitator required to provide students with the materials and opportunities to use the language (CDC 2007a, p. 29). Achieving learner-centeredness is only possible when the materials and conditions to use the language are motivating and interesting to the students so that they can engage in the text and tasks of the given lesson. The main assumption of learner-centred practice has been that "learning is a natural, constructive process where learning is most productive when it is relevant and meaningful to the learner, in positive learning environments" (Schuh, 2004: 835). Learner authenticity of the text and task 
both are thus very important aspects in promoting learner-centeredness.

Although learner-centeredness presupposes that the decision regarding the content and the form of teaching is made jointly by the teacher and students, the teacher's role is more crucial as s/he still performs the role of a knower and an organizer (Tudor, 1993) In the original text (CDC, 2007b), learner authenticity is not accounted for. The text is a letter about 'personal problems' but the problem as presented in the letter is not very common among Nepalese students, thus, less likely to motivate them. The input does not offer sufficient context and guidelines to the students and even the intrinsically motivated students may fail to carry out the activities as the task instructions are not sufficient and clear. For example, the activities $5 \mathrm{c}$ and $5 \mathrm{~d}$ (page 34 ) in original text give some example sentences and clues for students to make sentences but the examples do not precede any clues. I have supplemented both text and tasks (activities) in an attempt to link them with learners' personal experiences and to arouse their sympathy and empathy.

Another important aspect of learner authenticity is the attractive presentation of the text in the given materials. Even the genuine materials with appealing content may fail to attract learners if the presentation is not made attractive. The use of graphic, colour, pictures and other visual effects is a way of creating learner authenticity to some extent. However, in the Nepalese context, it is very difficult to achieve as attractive presentation is more costly. The government does not invest a lot in the education and parents cannot afford to buy expensive books. Therefore, cheaper, cost-effective text-books are published. As a result, the texts fail to attract learners at first sight. In the given unit, the pictures and figures are very small and even difficult to identify (e.g. pictures in activity $2,5,6$ ).In the proposed materials, I have tried to supplement those figures and pictures with pictures collected from magazines, the internet etc. Similarly, I have supplemented activities which bring detailed task instructions so as to help learners comprehend the task problem easily.
As the given textbook and curriculum are based on the CLT approach, tasks are not central to learning. However, they encourage teacher to use resources and materials so as to provide additional opportunities for student learning. In this sense, the tasks supplemented here can be seen as parts of 'task-supported learning and teaching' (Samuda and Bygate, 2008). In the original material, the activities that follow the text not only suffer contextual limitations but also lack relevance although there are some elements of task authenticity. For example, in activity $4 \mathrm{a}, 4 \mathrm{~b}$ and $5 \mathrm{~b}$, the students are required to pretend or role-play as different characters (Anil's Aunt, Anil and Father, Parent and Child) which constitute elements of rehearsal task representing real-world language use. However, there are some problems. For example in Activity 5b, the task requires students to engage in conversation but the intended outcome is a written dialogue. So I have proposed conversation performance by pair in real time. Similarly, pictures of personalities related to the students' national life and elaborated task instructions so as to link them with their everyday experiences have been added to incorporate elements of learner authenticity (Task, 2). The tasks that are directly related to reading text are supplemented with new tasks but the goal remains the same. With the purpose of offering variety and excitement to the students, I have incorporated word game (Task, 2), pair and group works. Language games can have elements of both learner and task authenticity as they are motivating, offer students with opportunity to be openly competitive as well as fun while requiring productive outcome.

Samuda et al. (2001) identify three components of a task which designers should ensure viz. input, operation of input and outcome. Input includes the pre-requisites like contextual information, textual-input, instruction questions, pictures or other simulated situations which the learners use as springboard to reach to a conclusion or product of some sort by processing and exploring the input individually or in a group. Wright (1987, p.48) suggests a task to comprise of 'instructional questions' that require learners to operate on. However, he does not see output as 
an important explicit component but as inherent in the instructional task. Nevertheless, teacher as a knower and a guide of learning, generally, have some sort of anticipation of the end product of the task which is inherent in the input data or in the form of instruction or the guidance given during the process of task completion. This anticipation can be termed 'discourse potential' (Ellis, 2003 p. 17) as it is not always possible to ensure that the intended outcome is achieved, although, teacher might use some interventions to lead the task process towards outcome.

In supplementing the given text and tasks, I have tried to incorporate both the text and learner authenticity into the framework of task. The supplemented tasks are designed so that students involve in genuine communicative activity. To use Nunan's (2004) classificatory continuum, most of the tasks supplemented are activation tasks, although Task 1.1 and Task 1.2.V (Appendix, 2) can be placed closer to the rehearsal end.

\section{Conclusion}

Skill in supplementation is essential for any teacher from the perspective of a communicative/functional curriculum. Even the text and tasks that are best designed may fail to obtain authenticity while used in a class. The material that proves authentic might fail to satisfy authenticity in different times and situations because the information that a text brings can be outdated with time. Moreover, the classroom situation might differ due to the affective variables (motivation, encouragement, and reward structure) in the participants (students, and teachers). Therefore, we should examine authenticity of materials with regard to these variables as well. As learners are in the centre of any educational program, materials developers or classroom teachers constantly need to understand their demands, needs and interest and manipulate and formulate tasks so that they become both motivating and cognitively challenging to them. While on the one hand, the English language print materials (newspapers, and magazines) are increasingly being available in the Nepalese context, the access to audio-visual media (Cable Television, and FM radio transmissions) are also increasing which could be exploited extensively in years to come, for offering relatively more authentic materials in language classroom. One the one hand, authentication of materials and tasks can be done more effectively by bringing media, and English language resources to the access of the classroom, the classroom teachers require to be equipped with skills of manipulating and even creating authentic materials on the other. The supplementary materials presented here can offer a model of how authenticity can be integrated. However, they require more such models which are verified and updated after piloting in the classroom situation and stakeholder (learner, and teacher) feedback.

Lekh Nath Baral teaches at Kathmandu Don Bosco Higher Secondary School. He is a former principal of SOS Hermann Gmeiner School, Surkhet. A NELTA life member and a Teacher Trainer, he did his MA in TESOL from Institute of Education, University of London under the Centenary Scholarship Scheme 2007. His research interest in ELT include Teachers' and Students' belief systems, Culture and Identity in Second Language Development, Materials Evaluation and Development, Role of Feedback on Learning, Impact of Networks in Professional Development.

\section{References}

Bachman, L. (1991). What does language testing have to Offer? TESOL Quarterly 25.4, 671-704.

Breen, M. P. (1985) Authenticity in the language classroom. Applied Linguistics 6/1:60-70.

Curriculum Development Centre (CDC) Nepal (2007a). Secondary school curriculum of Nepal. Sanothimi: CDC.

Curriculum Development Centre (CDC) Nepal. (2007b). Grade 10 English. Sanothimi: CDC.

Crystal, D. (1997). English as a global language. Cambridge: CUP.

Ellis, R (2003). Task-based language learning and teaching Oxford: OUP.

Guariento, W. \& Morley, J. (2001). Text and task authenticity in the EFL classroom. ELT Journal $55.4,347-353$.

Harmer, J. (2001). The practice of English language teaching. London: Longman.

Hoftun, M., Raeper, W. \& Whel, J. (1999). People, politics 
\& ideology: Democracy and social change in Nepal. Kathmandu: Mandala Books.

Kramsch, C. (1993). Context and culture in language teaching. Oxford: OUP.

Lee, W. Y. (1995). Authenticity revisited: Text authenticity and learner authenticity. ELT Journal 49/4:323328.

Littlewood, W. (1981). Communicative language teaching: An introduction. Cambridge: CUP.

Mishan, F. (2005). Designing authenticity into language learning materials. Bristol: Intellect

Nepal Mountain News (Online). (2008) Retrieved from http://www.nepalmountainnews.com/news. $\mathrm{php} / 2008 / 05 / 29 /$ celebrations-on-to-markrepublic-declaration.html on July 27, 2008.

Nunan, D. (1988). The learner centred curriculum .Cambridge: CUP.

Nunan, D. (1989). Designing tasks for the communicative classroom. Cambridge: CUP.

Nunan, D. (2004). Task-based language teaching .Cambridge: CUP.

Samuda, V. \& Bygate, M. (2008). Tasks in second language learning. Basingstoke: Pelgrave Macmillan.

Schuh, K. L. (2004). Learner-centred principles in teacher-centred practices? Teaching and Teacher Education 20: 833-846.

Tamang, B. L. (2008). A complete English practice book For Grade 10 \& SLC. Kathmandu: Asia Publications.
Taylor, D. (1994). Inauthentic authenticity or authentic inauthenticity?. TESL-EJ 1/2:1-11 retrieved from http://www-writing.berkeley.edu/TESL-EJ/ ejo2/a.1.html on July 15, 2008.

Tudor, I. (1993). Teacher roles in learner-centred classroom. ELT Journal 47/1:22-31.

Ur, P. (2008). The fully competent speaker of English as a lingua franca. A paper presented at IATEFL Conference, Exeter April 8, 2008.

Van Lier, L. (1996). Interaction in the language curriculum: Awareness, autonomy and authenticity. New York: Longman.

Widdowson, H. G. (1978). Teaching language as communication. Oxford: OUP.

Widdowson, H. G. (1979). Explorations in applied linguistics Vol. 1 \& 2. Oxford: OUP.

Widdowson, H. G. (1998). Context, community, and authentic language. TESOL Quarterly 32/4:705716.

Widdowson, H. G. (2003). Defining issues in English language teaching. Oxford: OUP.

Wright, T. (1987). Instruction task and discoursal outcome in L2 classroom. In C. N. Candlin \& D. F. Murphy (Eds.) Language learning tasks. London: Prentice Hall pp 48-68.

Young, R. (1980). Modular course design. In ELT Documents: Projects in Material Designs, Hemel Hempstead: Macmillan/The British Council [cited in Lee 1995:324]

\section{Appendix I: Supplementary Materials}

\section{Lesson I: Expressing Problems and Suggesting Solutions}

\begin{tabular}{|c|c|c|}
\hline Task & Instruction to students & Instruction to teachers \\
\hline 1. & $\begin{array}{l}\text { Discuss you answer to following questions with } \\
\text { your friends. } \\
\text { utes) } \\
\text { (10 min- } \\
\text { i. Have you faced any problem re- } \\
\text { cently? What is that? } \\
\text { ii. Is your problem solved now? How? }\end{array}$ & $\begin{array}{l}\text { Talk about a situation when there was a real } \\
\text { problem at school or in the society. } \\
\text { For example: } \\
\text { We are planning an educational trip } \\
\text { next month. Do you think all of you } \\
\text { will be able to go? What might be the } \\
\text { causes that make it difficult for you to } \\
\text { go? Could those difficulties be solved? }\end{array}$ \\
\hline
\end{tabular}




\begin{tabular}{|c|c|c|}
\hline 2. & $\begin{array}{l}\text { Read the following letter and do the activities. } \\
\text { I. Why is Seema's father not ready to send her on the } \\
\text { excursion? Make a list of reasons. } \\
\text { minutes) } \\
\text { II. (Share with your partner )Do you think those reasons } \\
\text { are realistic? Why? } \\
\text { III. Suppose you are her friend and you came to know } \\
\text { about her problem. Write a letter to Seema giving } \\
\text { advice on how she can convince her father or offering } \\
\text { your help to solve the problem. } \\
\text { IV. Share your letter with your partner and find out if your } \\
\text { friend has given different advices. } \\
\text { minutes) } \\
\text { V. Work in a group of four (two pairs). Imagine that } \\
\text { you are going to talk to Seema's father to convince } \\
\text { him to allow Seema to go on the trip. What would } \\
\text { you say? What would Seema's Father say? Perform } \\
\text { the conversation to your friends and listen to their } \\
\text { conversation. } \\
\text { (10 minutes) }\end{array}$ & $\begin{array}{l}\text { Tell the students that the letter was } \\
\text { written by one of the students like } \\
\text { them and many of the students may } \\
\text { face similar situation. } \\
\text { Assign students into pairs and en- } \\
\text { courage them to speak with each } \\
\text { other. }\end{array}$ \\
\hline
\end{tabular}

July, 22, 2008

Dear Matrika sir

Katunje, Bhaktapur, Nepal

Namaste

I am very much interested to go on educational tour coming month. Actually, I am very much excited about it because we can see cultural sites of different kinds. I also talked to my parents about it but my father has not allowed me to go to the trip. He says that it is not good to stay away from home for such long time without parents or family because I am a girl. I know that there will be no one to help my parents when I am away as my brother is busy preparing for his examinations. He is more concerned because there will be no one to collect fodder for buffalos if I go on the tour. Although my brother has agreed to help him by collecting fodder during my absence, my father does not want him to work because he has to study hard and get good marks. He does not believe that going on a tour also has educational importance. He says it is waste of money and time.

I know that the excursion has educational benefits and I have tried to convince my father. In spite of my attempts to convince him, he sees no benefits of going on a tour.

As my father is not happy and does not give me the money required for the trip, I am sorry to tell that I cannot go on the trip. I will be happy if you can help me in convincing my father so that I do not miss this opportunity to travel with friends and learn new things about places and people.

Thank you.

Your faithful student,

Seema 
Photographs for the tasks in the following lesson (Lesson 2)
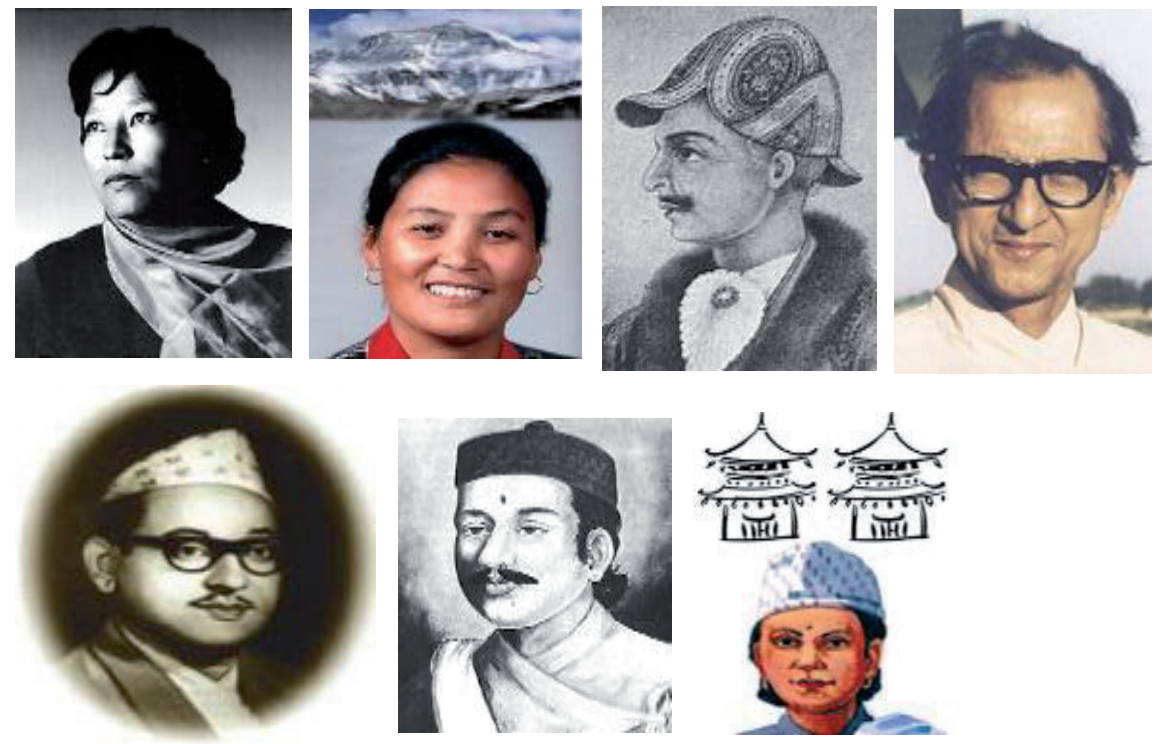

\section{Lesson 2: Expressing Reasons and Purpose}

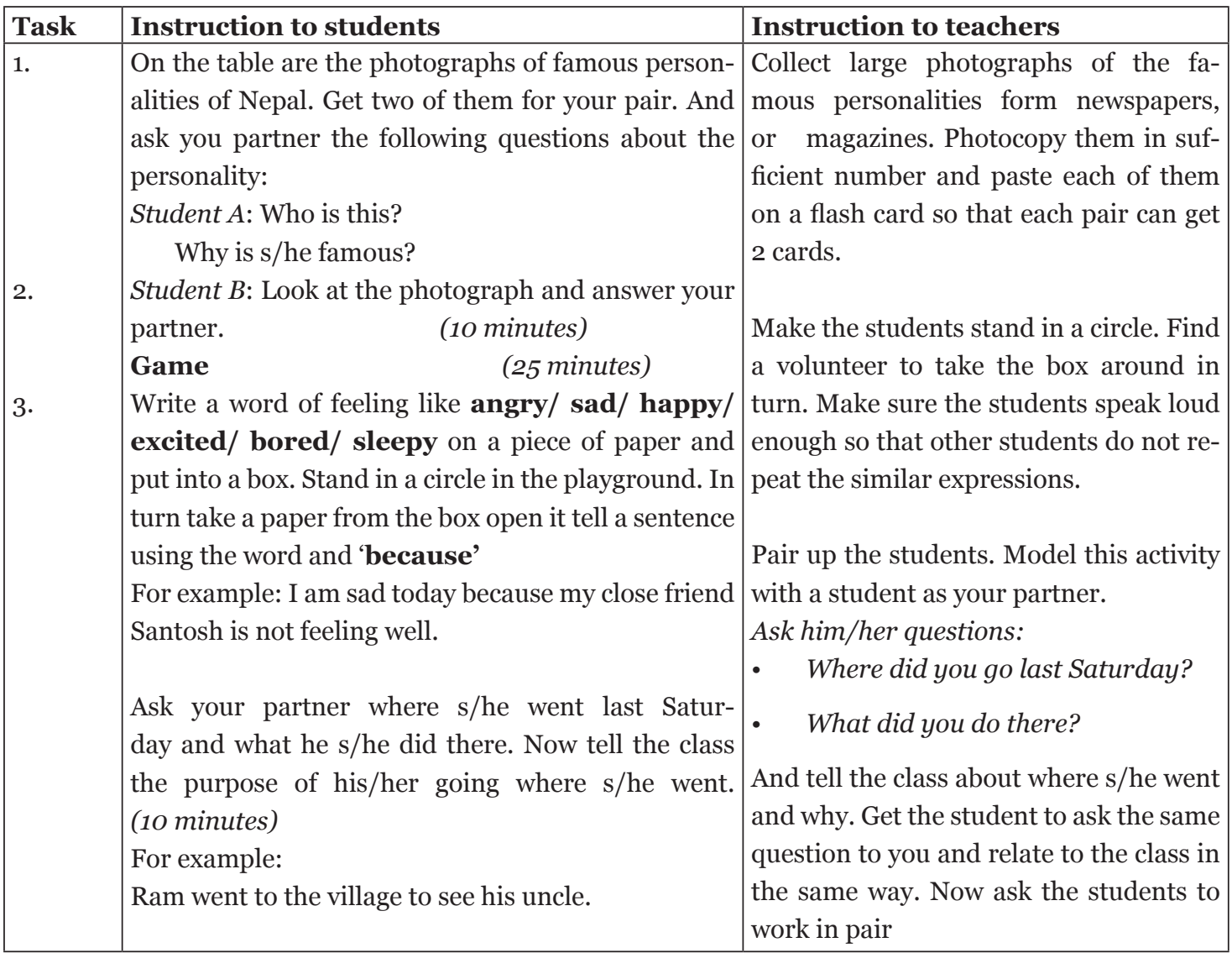




\section{Lesson 3: Expressing Contrasts (Unexpected Results)}

\begin{tabular}{|c|c|c|}
\hline Task & Instruction to students & Instruction to teachers \\
\hline 1. & $\begin{array}{l}\text { Think and answer to your partner ( } 5 \text { minutes) } \\
\text { - Who is put in a jail? } \\
\text { Is it possible for an innocent person to be } \\
\text { jailed? } \\
\text { Work in groups of three. Look at the following } \\
\text { example and follow the instructions. } \\
\text { (25 minutes) } \\
\text { Example: hungry- not want to eat anything } \\
\text { i) Bandana is hungry. She does not want to } \\
\text { eat anything } \\
\text { ii) Although Bandana is hungry, she does } \\
\text { not want to eat anything. } \\
\text { iii) In spite of her hunger, Bandana does } \\
\text { not want to eat anything. } \\
\text { Intelligent- failed the exam } \\
\text { Rich- live in an old house } \\
\text { Good sportsmanship - lost the match } \\
\text { Giant body - cannot pick up even a small bag } \\
\text { Honest- not trusted by others } \\
\text { Student1: Write a pair of contrasting sentences } \\
\text { with the help of the clues given and pass them } \\
\text { to your student } 2 \\
\text { Student } 2 \text {. Connect the sentences using } \\
\text { 'Although' and Pass on to student } 3 \\
\text { Student } 3 \text {. Rewrite the sentence using In spite } \\
\text { of Now start with Student } 2 \text { and continue the } \\
\text { same process with the clues. } \\
\text { experienced or heard of. Write any } 4 \text { sentences } \\
\text { using 'although' to express such contrasts. } \\
\text { (15 minutes) }\end{array}$ & $\begin{array}{l}\text { Create context in the form of a talk. } \\
\text { E.g. Though we normally do not expect an } \\
\text { innocent person to be jailed, it is sometimes } \\
\text { possible. There are some examples of such } \\
\text { contrasts. } \\
\text { 1. I am hungry. I don't want to eat } \\
\text { anything } \\
\text { 2. Hari is efficient. He never fin- } \\
\text { ishes his job in time. } \\
\text { 3. He was careless. He drove } \\
\text { home safe. } \\
\text { Such situations are unexpected and are } \\
\text { called contrasts. Have you ever heard, seen } \\
\text { or experienced such contrasts? Tell your } \\
\text { partner ifyou have experienced any of them. } \\
\text { Divide students in groups of three. Before } \\
\text { students start working, make sure they have } \\
\text { understood what they are required to do. You } \\
\text { can ask a group to model in front of the class. } \\
\text { Ask a volunteer student to come in front of } \\
\text { the class and describe any contrast s/he has } \\
\text { seen or experienced before students start } \\
\text { writing. }\end{array}$ \\
\hline
\end{tabular}

\section{Lesson 4: Giving Explanation}

1. The following is part of the explanation letter written by Ram to his teacher for being absence in school for more than a week. Fill in the gaps using because, although, so that, to (in order to), in spite of whichever is appropriate. (20 minutes)

I was absent for a week ............my father was seriously ill and was admitted in Hospital. I had to be there .I could help him go to the toilet and put on his dress. my sister was at home and doesnot need to go to school, she could not look after my father she has to study hard for her examinations. ..I had written an application for leave, I could not find anyone to deliver 
it to the school. I tried to call at the school...........inform you about my situation but the telephone was not being received. desire and attempts to come to school after 2-3 days, it was not possible my father was discharged only after a week.

2. Now write a paragraph about yourself using the highlighted words. (25 minutes)

(Teachers note: 1 . Instruct students to work individually. After they fill in the gaps ask them to compare with their partners. Let them discuss on the points of difference, if any, and correct their work.)

\section{Supplementation for Activity 2 of original materials}
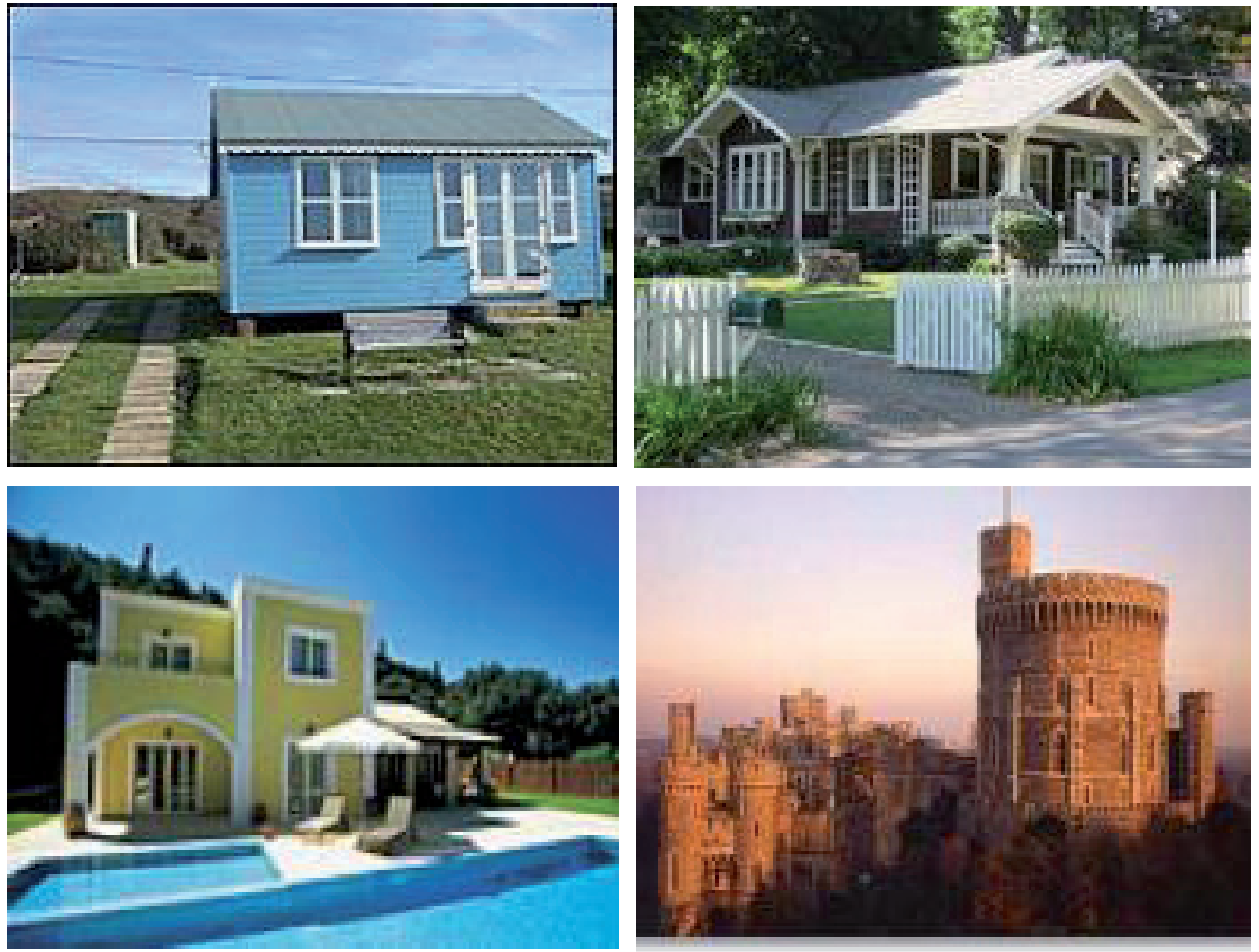

1. Read the description of different kinds of house seen in the picture and match the description with the picture it describes.

i) Castle: A building with many defences often resided by kings.

ii) Bungalow: A one-storied house with a low-pitched roof.

iii) Hut: A small wooden shed. A primitive form of house.

iv) Villa: A house, often larger and more expensive than average, in the countryside or on the coast, often used as a retreat. 